\title{
Conductivity distribution and seismicity in the northeastern Japan Arc
}

\author{
Yukio Fujinawa ${ }^{1}$, Noriaki Kawakami ${ }^{2}$, Jun Inoue ${ }^{2}$, Theodore H. Asch ${ }^{2}$, and Shinji Takasugi ${ }^{3}$ \\ ${ }^{1}$ National Research Institute for Earth Science and Disaster Prevention, Tennohdai 3-1, Tsukuba-shi, Ibaraki 305-0006, Japan \\ ${ }^{2}$ Geothermal Energy Research and Development Co., Ltd., 11-7, Kabuto-cho, Nihonbashi, Chuo-ku, Tokyo 103-0026, Japan \\ ${ }^{3}$ Geothermal Engineering Co., Ltd., 804, Koami-cho, Nihonbashi, Chuo-ku, Tokyo 103-0016, Japan
}

(Received January 22, 2001; Revised December 27, 2001; Accepted January 14, 2002)

\begin{abstract}
Wideband magnetotelluric (MT) observation data were obtained from 91 sites along six transects in the central part of the Japan Arc. Here, a quasi-3D georesistivity distribution, in addition to other geophysical and geological parameters, is used to better understand seismicity in the region. We found that high seismicity in the Central Mountain Range is due to relatively poor fluid saturation caused by volcanism. The high conductive fracture zone in the west of the Central Basin without big earthquakes is characterized by a low Poisson ratio. It is suggested that strains cannot be accumulated in those regions. The Miyagi-ken-hokubu region with a frequent occurrence of large earthquakes, is conductive- high Poisson ratio- high $V p$ suggesting that the zone is relatively fluid-rich and brittle.
\end{abstract}

\section{Introduction}

In order to understand tectonics, seismicity, geology and metamorphic activity, an extensive magnetotelluric (MT) survey was conducted in the central part of the northeastern Japan Arc (Fujinawa et al., 1997, 1999; Kawakami et al., 1997) following previous observations of Utada (1987), Ogawa (1992) and Nabetani and Fukuta (1995). A quasi-3D georesistivity distribution was obtained by using broadband MT data corrected sub-surface distortion due to the 3-D heterogeneity. Some of the seismicity is explained on the basis of resistivity contracts, faults, or geological lineaments (Fujinawa et al., 1999). We used the relation of the conductivity data with the presence of saline fluid and partial melting (Jones, 1992; Simpson, 1998; Chen et al., 1996).

There remains, however, ambiguity in the correspondence between seismicity and those geophysical parameters. For instance, the Central Mountain Range and Dewa Hill are both highly resistive, but there are clear differences in seismicity. For the sake of finding other hidden parameters controlling seismicity, here we examine the seismic velocity and the Poisson ratio. Those parameters have been shown to be useful to discriminate the crustal regime of seismogenetic zones (Zhao et al., 1992; Zhao and Negishi, 1998; Umino and Hasegawa, 2002). The present work shows that the seismic velocity and the Poisson ratio, in addition to conductivity data, are effective parameters to characterize the conditions of the crust from the point of view of seismicity.

\section{Data}

Magnetotelluric observation data are briefly described here (see Fujinawa et al., 1997, 1999). Broadband magnetotelluric data were acquired along six traverses (A, B, C, D,

Copy right (C) The Society of Geomagnetism and Earth, Planetary and Space Sciences (SGEPSS); The Seismological Society of Japan; The Volcanological Society of Japan; The Geodetic Society of Japan; The Japanese Society for Planetary Sciences.
E, F) in the central part of the northeastern Japan Arc running approximately east-west from the coastal area of the Pacific Ocean to that of the Japan Sea (Fig. 1). The survey in the northern part consisting of three shorter transects (D, E, F), was supplemented by the investigation of conductivity heterogeneity along the arc axis after the main phase of observation. The geological and tectonic setting can be found in previous papers (e.g. Ogawa et al., 1992; Fuginawa et al., 1997).

A five-component magnetotelluric field in the wide frequency range of $0.0018 \mathrm{~Hz} \sim 20 \mathrm{kHz}$ was obtained. The remote reference technique (Gamble et al., 1979) was adopted in order to minimize the effects of noise. Several steps to improve data quality were taken, besides the remote reference technique, such as smoothing the impedance tensor in the frequency domain through the 1-D Bostic model. Results of the 1-D Bostic inversion of the TM mode along all six traverses are shown in Fig. 2. Beside extraneous noises in the MT observation, we corrected the near surface 3-D heterogeneity effect to obtain more plausible 2-D model by means of the Groom-Bailey tensor decomposition (GBD) method (e.g. Groom and Bailey, 1989). The site-gain factor was determined by using the results of the transient electromagnetic measurement (TEM) at all observation sites. The electrical resistivity structure in the survey region was shown to be nearly two-dimensional (Fujinawa et al., 1997; Kawakami et al., 1997). So, for simplicity, we assumed that the regional strike in the 2-D modeling is N-S. The 2-D MT inversion algorithm, GRRI (Lee et al., 1995; Yamane et al., 1996) was used, extending to the RRI algorithm developed by Smith and Booker (1991). Effects of the Pacific Ocean and the Japan Sea are considered by assuming a $50 \mathrm{~m}$ thick surface layer with a resistivity of $0.2 \Omega \cdot \mathrm{m}^{-1}$ (salt water), extending out from the coast.

The final TM mode 2-D models along the three long tra- 


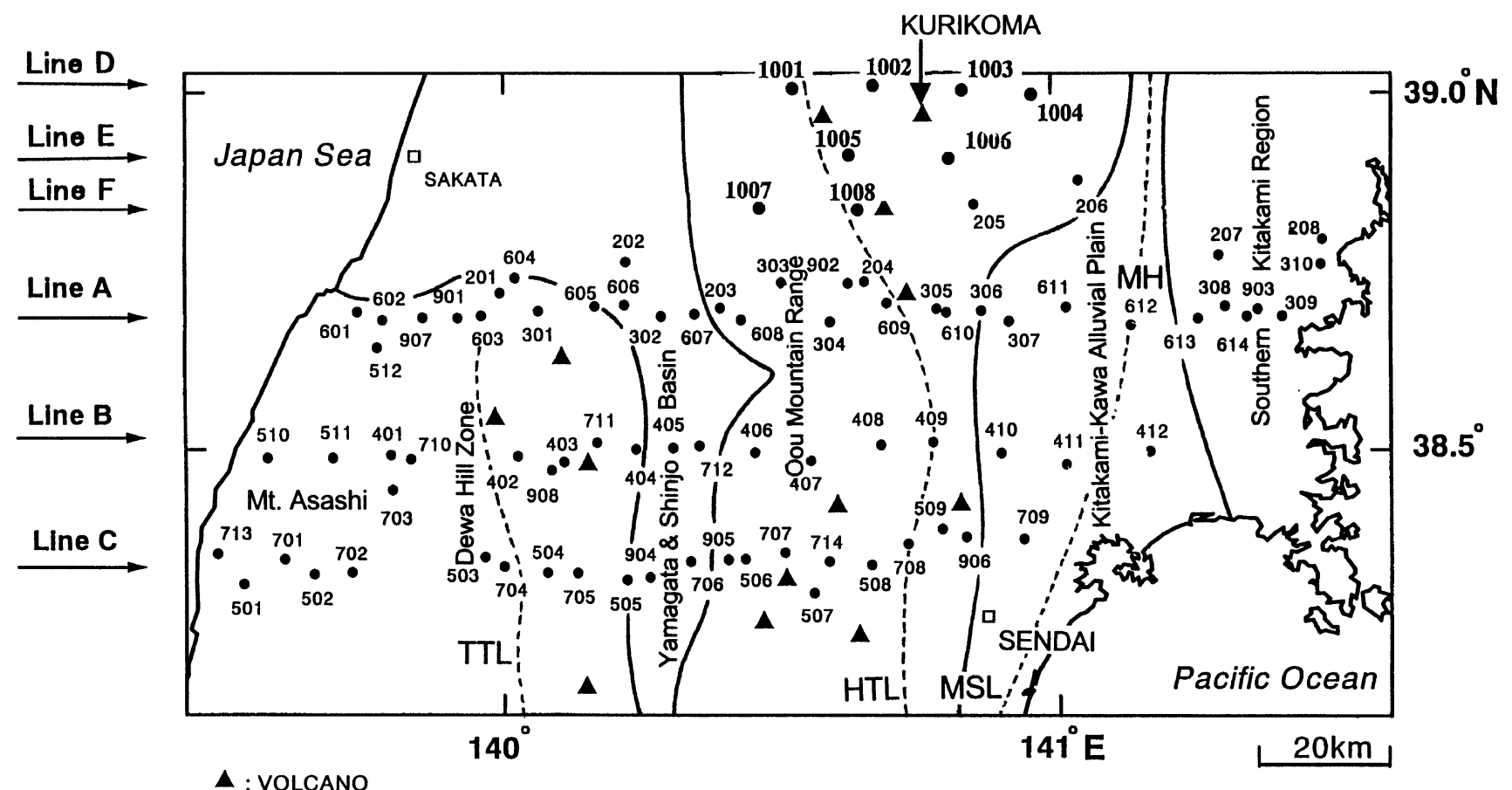

Fig. 1. (a) Simplified geological maps of the northeast Japan arc in the pre-Tertiary and the three MT profiles, Lines A, B and C (Fujinawa et al., 1997). Miocene and Quaternary volcanic fronts are shown with several tectonic lines. The MT transects north of the present study area (Akita-Iwaizumi) and south of the present study area (Niigata-Abukuma) surveyed by Ogawa (1992) are shown. The northernmost parts have been surveyed by Nabetani and his group (Nabetani et al., 1992); (b) Location of the MT measurement sites (Line A: +, Line B: $*$, Line C: $\times$ ) and geologic divisions (after Geological Survey of Japan, 1995). Triangles denote Quaternary volcanoes. TTL is the Tanakura tectonic line and HTL is Hatagawa tectonic line. TEM measurement was also conducted at each site.

verses are seen in figures 3, 5 and 6 of Fujinawa et al. (1999). Though we obtained the 2-D models for both the TM and TE, as well as for joint modes, we did not succeed in obtaining reasonable TE and joint-mode solutions. Therefore, the TM solution is used in the following discussion. Seismic velocities are calculated using the algorithm made by Prof. Zhao, based on the 3-D seismic velocity inversion results using data from an extensive seismic network (Hasegawa et al., 1991).

\section{Analysis}

The Central Mountain Range is seen to be resistive also in the northern transects (D, E and F Lines). It was found that resistivity is not uniform along the arc axis, but decreases toward the north: the northernmost Line $\mathrm{E}$ is less resistive $\left(\sim 200 \Omega \cdot \mathrm{m}^{-1}\right)$ in comparison with higher resistivity $\left(\sim 1,000 \Omega \cdot \mathrm{m}^{-1}\right)$ in the southern part. The transition region is around the active volcano Mt. Kurikoma between Lines $\mathrm{E}$ and $\mathrm{F}$ (Fig. 1).

The axial change of resistivity is interesting in relation to the variable depth limit of the seismicity in the upper crust (Umino and Hasegawa, 2002). The depth has been assumed to correspond to the brittle-ductile transition (Honkura, 1988; Schults and Crosson, 1996). The seismic depth limit is shallower in the geothermal region around Mts. Kurikoma, Onikoube, and Naruko, situated in northernmost part of the survey area (solid triangle in Fig. 1). Umino and Hasegawa (2002) attributed the depth variation to a variation in temperature employing the method of Sato et al. (1989) using the seismic data and the Curie point depths.

The gradual decrease of the critical depth northward from Line C to Line A (Umino and Hasegawa, 2002) corresponds to the northward decrease of resistivity in the Central Mountain Range. However, the abrupt resistivity decrease between Lines $\mathrm{E}$ and $\mathrm{F}$ does not correspond to the critical depth of seismicity in the upper crust. It is expected that the discrepancy can be understood through the use of conductivity and other geophysical data of larger spatial resolving powers that is currently available.

Here we will limit our discussion to variable seismicity in the upper and lower crust. Horizontal distribution of resistivity in the upper and lower crust is taken at depths of 7.5 and $22.5 \mathrm{~km}$, respectively, on the grounds of a crust thickness of $30 \mathrm{~km}$ there (Horiuchi et al., 1982). Six 2-D resistivity vertical profiles are interpolated using the spline function to obtain a quasi-3-D resistivity image in the area. The conductivity distribution in the upper crust is shown in Fig. 3(b).

In Fig. 3(a), the spatial distribution of the hypocenters of earthquakes in the upper crust, with focal depths from 0 to $15 \mathrm{~km}$, is overwritten on the resistivity distribution in the upper crust. The earthquake data are from the seismic database at Tohoku University (Hasegawa et al., 1991; figure 5 of Fujinawa et al., 1999). Historical earthquakes are indicated by star symbols (々). In Fig. 3(a), the preTertiary tectonic lines, Tanakura (TTL), Hatagawa, (HTL), and Morioka-Shirakawa (MSL) are included with the Quaternary Volcanic Front (VF). Seismic activity in relation to georesistivity has been previously discussed (see Fujinawa 


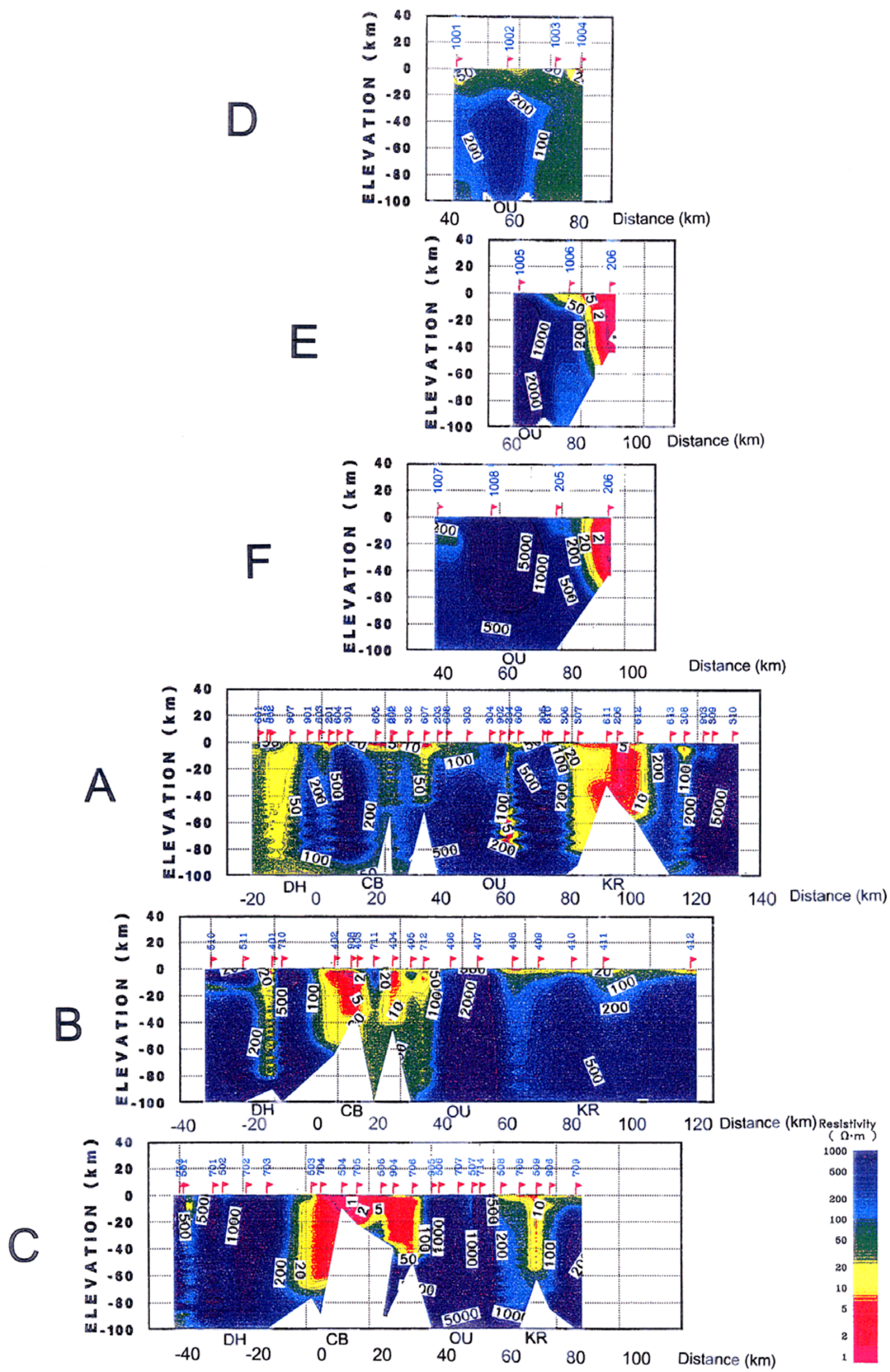


a Seismicity

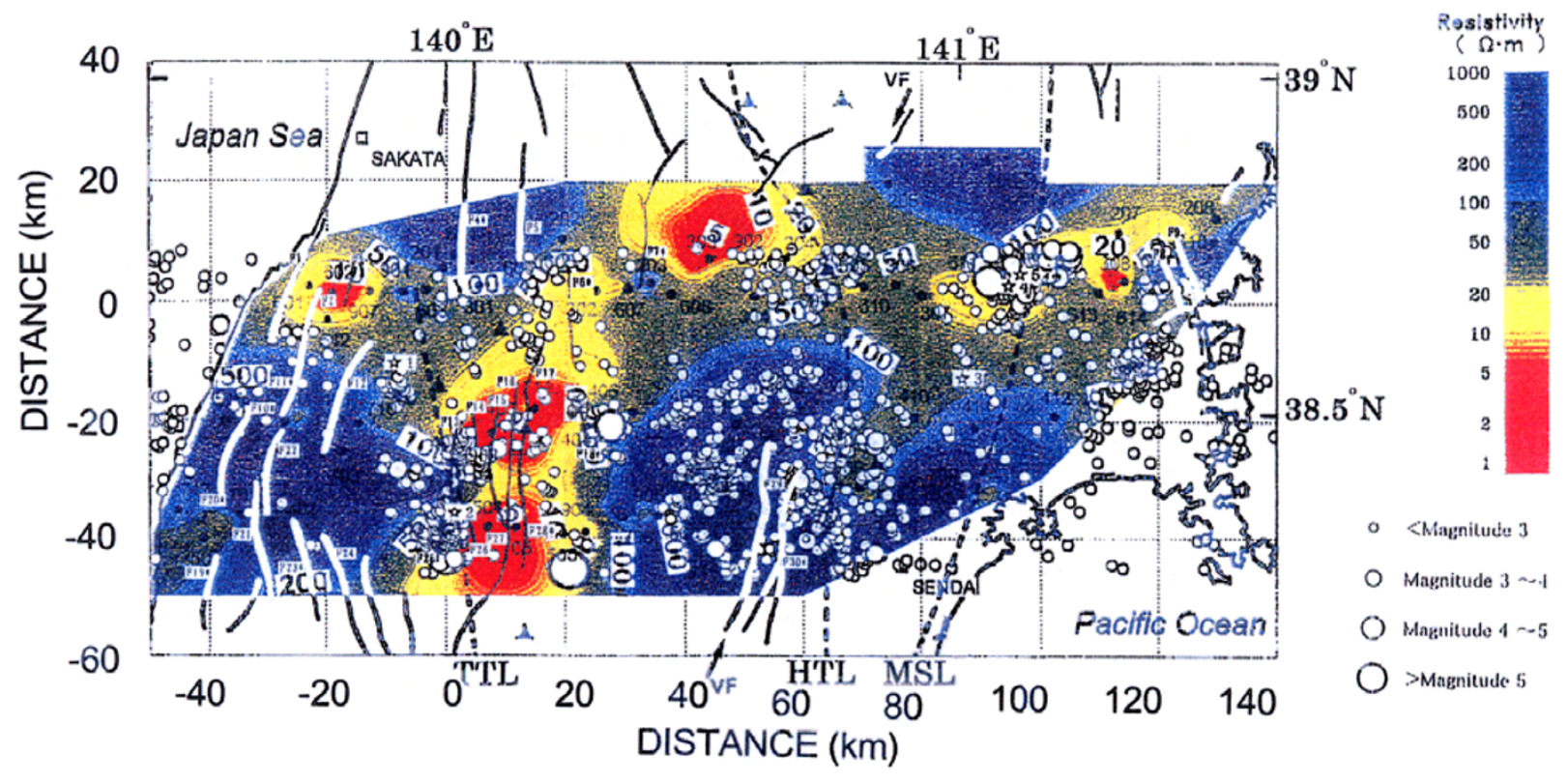

\section{b Resistivity (Depth: $7.5 \mathrm{~km})$}

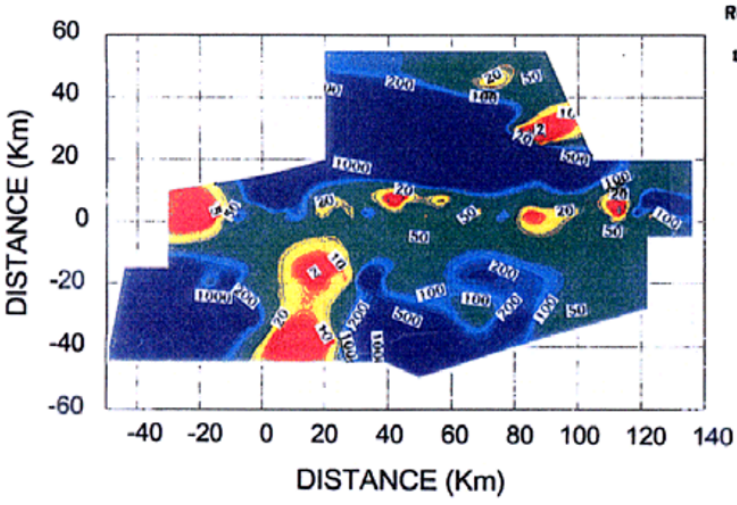

C Vp Distribution Map (Depth: $7.5 \mathrm{~km}$ )
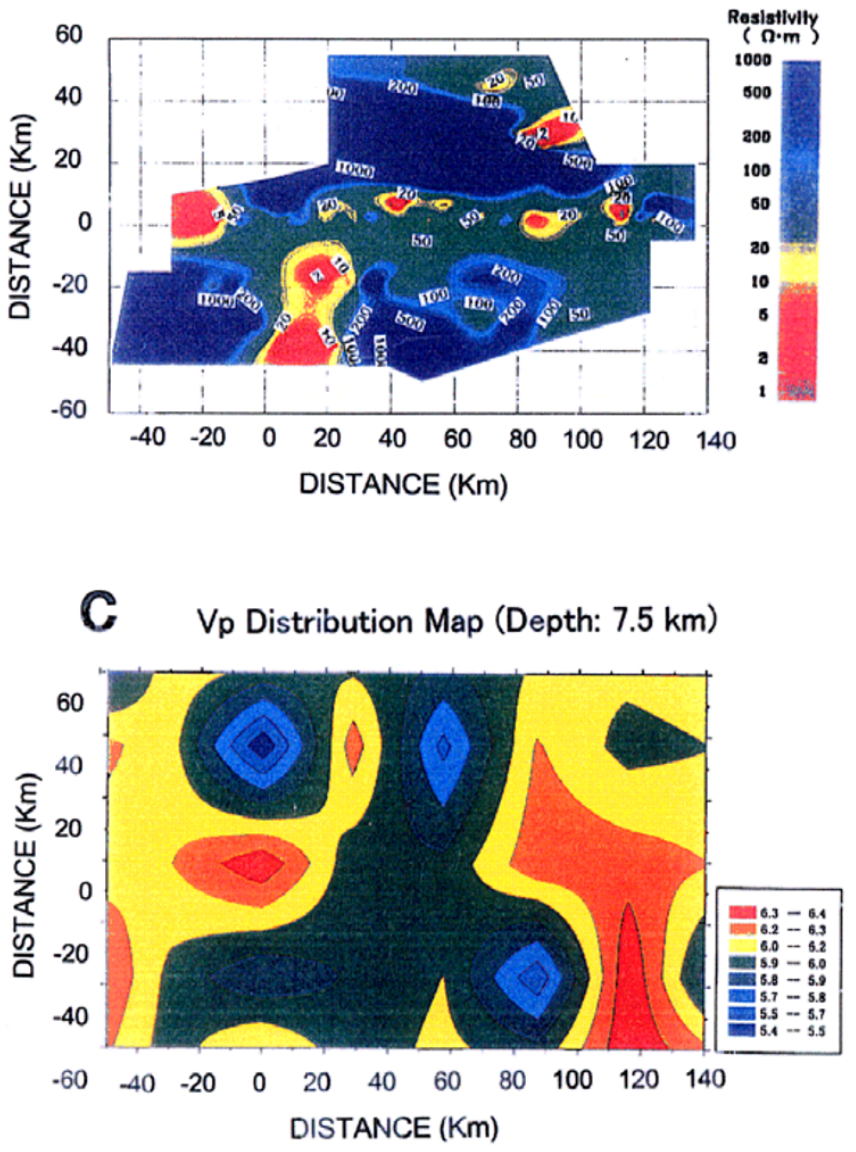

d Poisson's Ratio Distribution Map (Depth: $7.5 \mathrm{~km}$ )

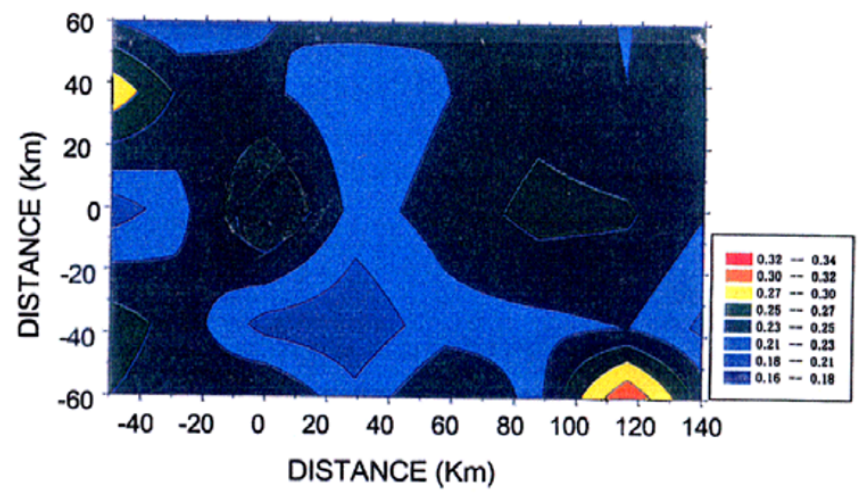

e Vs Distribution Map (Depth: $7.5 \mathrm{~km}$ )

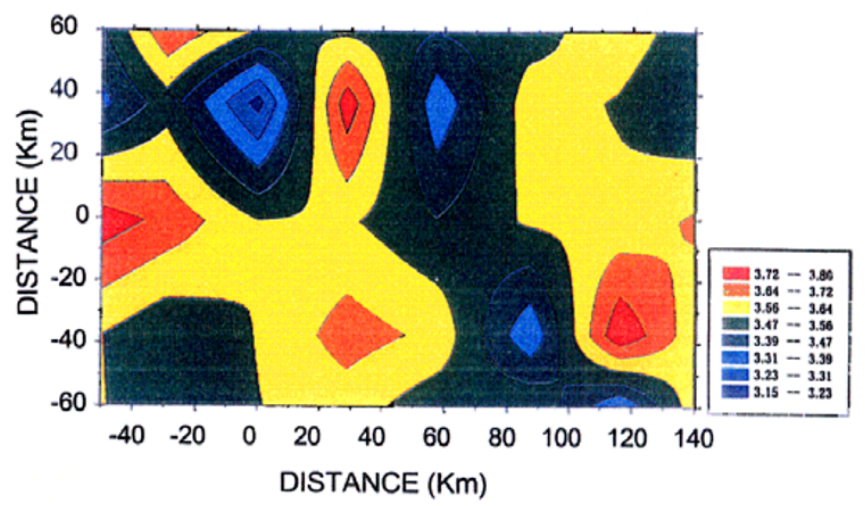

Fig. 3. (a) Seismicity in the upper crust in the central part of the northeastern Japan Arc overwritten by resistivity and active faults (from figure 5 of Fujinawa et al., 1999). Horizontal resistivity distribution at a depth of $7.5 \mathrm{~km}$, within the upper crust, is overlain by earthquake hypocenters determined by Tohoku University's dense seismic network and by noted historical earthquakes. Solid curves attached with number F* indicate active faults (Active Faults Research Group, 1991). The solid curve with the mark F indicates active faults or lineaments (Geological Survey of Japan, 1995). TTL = TANAKURA Tectonic Line, HTL = HATAGAWA Tectonic Line, MSL = MORIOKA-SHIRAKAWA line and VF = volcanic front. (b) Horizontal resistivity distribution in the upper crust at a depth of $7.5 \mathrm{~km}$ using six 2-D models for the MT mode. The seismic velocity $V p$ (c), $V s$ (d) and the Poisson ratio (e) are also shown using the data of Zhao et al. (1992). 


\section{a Seismicity}

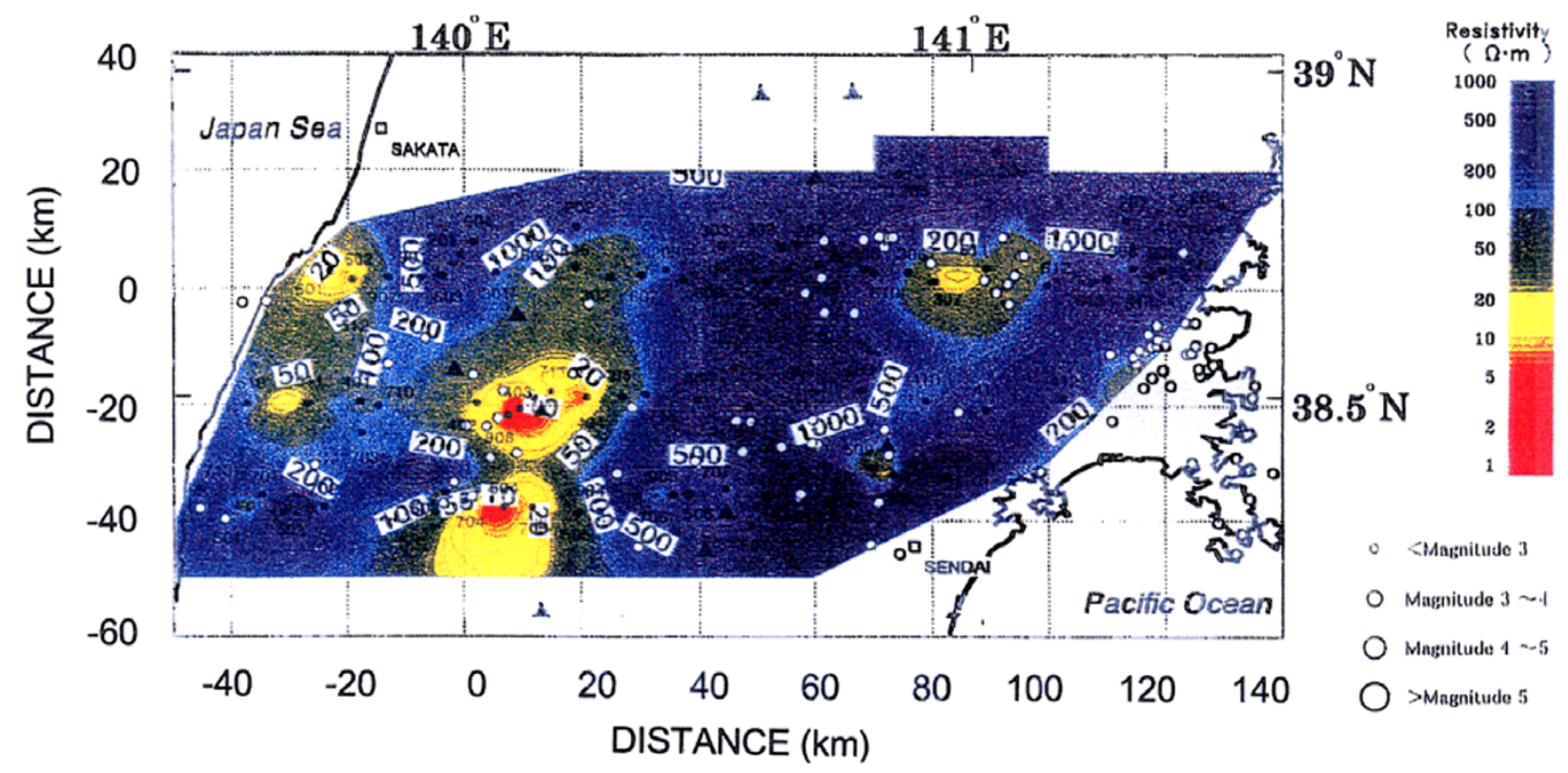

\section{b}

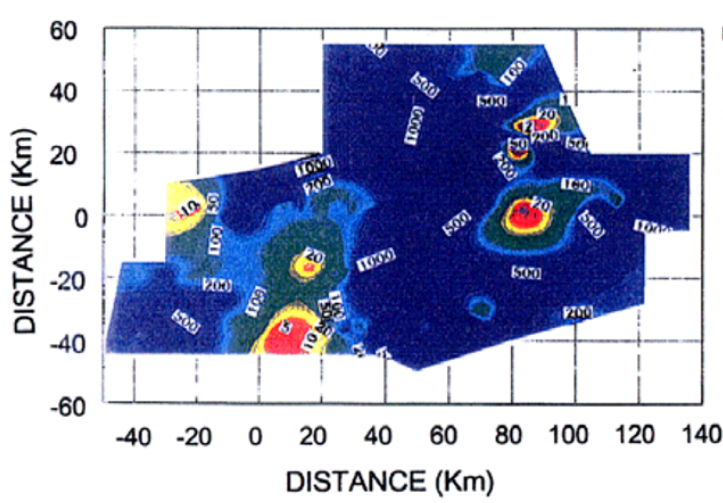

C Vp Distribution Map (Depth: $22.5 \mathrm{~km}$ )

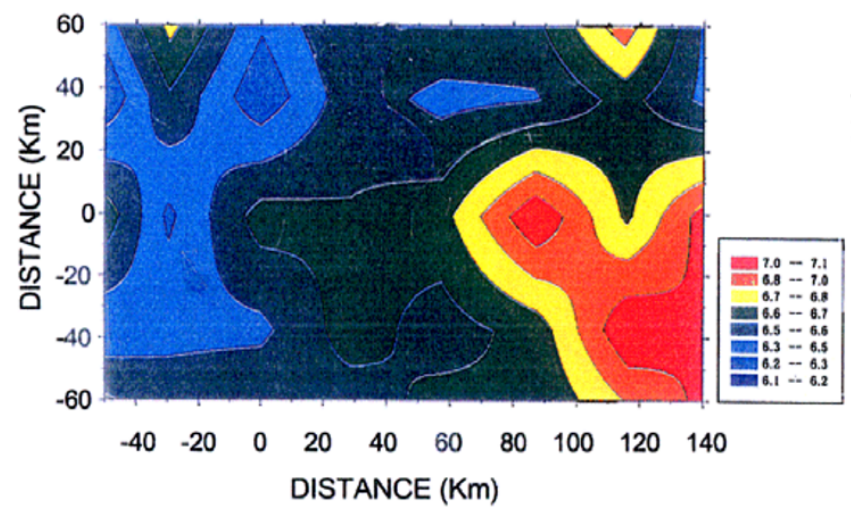

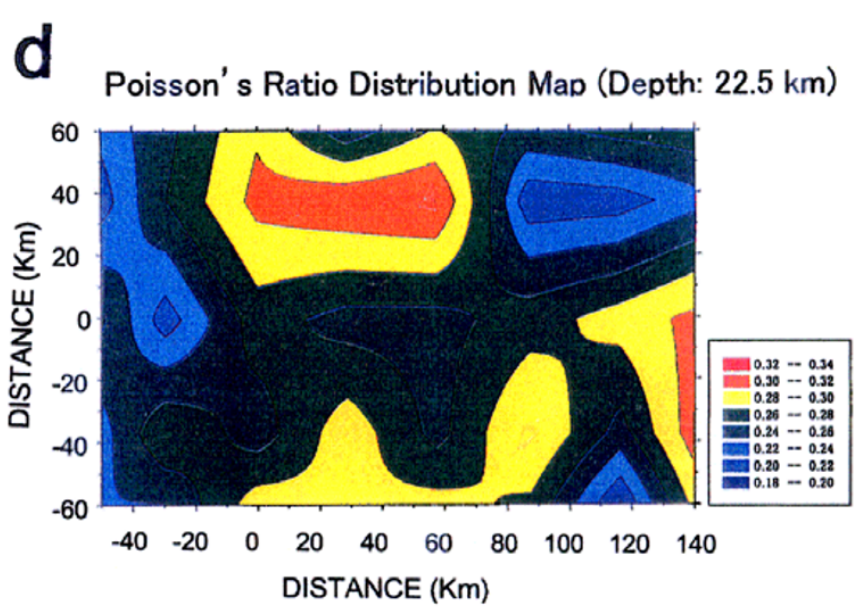

e Vs Distribution Map (Depth: $22.5 \mathrm{~km}$ )

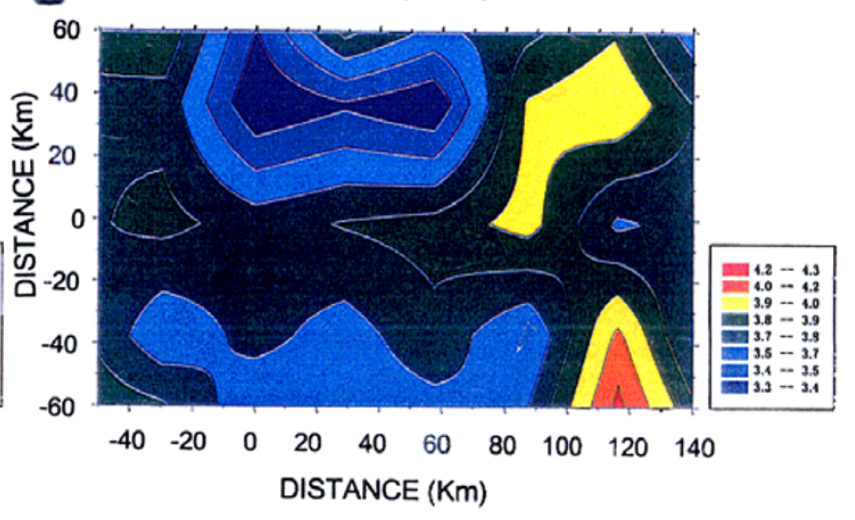

Fig. 4. The same as Fig. 3 except in the lower crust at a depth of $22.5 \mathrm{~km}$. 
Table 1. The characteristics of the geophysical and geological parameters in the upper crust of a typical zone in terms of seismicity.

\section{Upper Crust}

\begin{tabular}{|c|c|c|c|c|c|c|c|}
\hline Zone & $\begin{array}{l}\rho(\Omega \cdot m) \\
5 \sim 1,000\end{array}$ & $\begin{array}{c}\mathrm{Vp}(\mathrm{Km} / \mathrm{s}) \\
5.5 \sim 6.2 \\
\mathrm{Av} .=5.85\end{array}$ & $\begin{array}{c}\mathrm{Vs}(\mathrm{Km} / \mathrm{s}) \\
3.2 \sim 3.7 \\
\mathrm{Av} .=3.45 \\
\end{array}$ & $\begin{array}{c}\sigma \\
0.20 \sim 0.30 \\
\text { Av. }=0.25 \\
\end{array}$ & Fault & $\begin{array}{c}\text { Tectonic } \\
\text { Line } \\
\end{array}$ & Seismicity \\
\hline Mt. Asashi & $\begin{array}{l}(>500) \\
+45 \%\end{array}$ & $\begin{array}{c}(6) \\
+2.6 \%\end{array}$ & $\begin{array}{c}(3.5) \\
+1.5 \%\end{array}$ & $\begin{array}{l}(0.24) \\
-4 \%\end{array}$ & Many & TTL & $\begin{array}{c}\text { Inactive } \\
\text { (c.f. M5.8 1706) }\end{array}$ \\
\hline $\begin{array}{l}\text { Fracture } \\
\text { Zone }\end{array}$ & $\begin{array}{c}(5) \\
-60 \%\end{array}$ & $\begin{array}{l}(5.9 \sim 6.0) \\
+1.7 \%\end{array}$ & $\begin{array}{c}(3.6) \\
+4.4 \%\end{array}$ & $\begin{array}{c}(0.20) \\
-20 \%\end{array}$ & Many & TTL & $\begin{array}{c}\text { Active } \\
\text { M5.5 (1994) } \\
\text { on TTL }\end{array}$ \\
\hline $\begin{array}{l}\text { Central } \\
\text { Basin }\end{array}$ & $\begin{array}{c}(5) \\
-60 \%\end{array}$ & $\begin{array}{l}(5.9 \sim 6.9) \\
+1.7 \%\end{array}$ & $\begin{aligned} & (3.6) \\
+ & 4.4 \%\end{aligned}$ & $\begin{array}{c}(0.20 \sim 0.22) \\
-16 \%\end{array}$ & Many & None & $\begin{array}{c}\text { Active } \\
M>5 \text { at } \\
\text { Eastern Boundary }\end{array}$ \\
\hline $\begin{array}{l}\text { Oou } \\
\text { Mountain } \\
\text { Range }\end{array}$ & $\begin{array}{c}(1,000) \\
\text { (north:100) } \\
+62 \% \\
\end{array}$ & $\begin{aligned} & (6.0) \\
+ & 2.6 \%\end{aligned}$ & $\begin{array}{c}(3.5 \sim 3.7) \\
+4.4 \%\end{array}$ & $\begin{array}{c}(0.20 \sim 0.22) \\
-16 \%\end{array}$ & Two & $\begin{array}{l}\text { VF } \\
\text { HTL }\end{array}$ & $\begin{array}{c}\text { Active (VF) } \\
\text { M3 } \sim 4\end{array}$ \\
\hline $\begin{array}{l}\text { Miyagi-ken- } \\
\text { Hokubu }\end{array}$ & $\begin{array}{c}(30) \\
-20 \%\end{array}$ & $\begin{array}{c}(6.2) \\
+6.0 \%\end{array}$ & $\begin{array}{c}(3.5) \\
+1.5 \%\end{array}$ & $\begin{array}{l}(0.25) \\
0 \%\end{array}$ & None & MSL & Very Active \\
\hline
\end{tabular}

Table 2. The same as Table 1 except in the lower crust.

\section{Lower Crust}

\begin{tabular}{|c|c|c|c|c|c|c|c|}
\hline Zone & $\begin{array}{l}\rho(\Omega \cdot \mathrm{m}) \\
5 \sim 1,000\end{array}$ & $\begin{array}{l}V p(\mathrm{Km} / \mathrm{s}) \\
6.3 \sim 7.0 \\
A v .=6.6\end{array}$ & $\begin{array}{c}\mathrm{Vs}(\mathrm{Km} / \mathrm{s}) \\
3.4 \sim 4.1 \\
\mathrm{Av} .=3.75\end{array}$ & $\begin{array}{c}\sigma \\
0.2 \sim 0.3 \\
A v .=0.25\end{array}$ & Fault & $\begin{array}{l}\text { Tectonic } \\
\text { Line }\end{array}$ & Seismicity \\
\hline Mt. Asashi & $\begin{array}{c}(100 \sim 200) \\
+18 \%\end{array}$ & $\begin{array}{c}6.4 \sim 6.5) \\
-2 \%\end{array}$ & $\begin{array}{c}(3.6) \\
-4 \%\end{array}$ & $\begin{array}{c}(0.25 \sim 0.26) \\
+4 \%\end{array}$ & Many & TTL & Slight \\
\hline $\begin{array}{l}\text { Fracture } \\
\text { Zone }\end{array}$ & $\begin{array}{l}(5 \sim 10) \\
-97 \%\end{array}$ & $\begin{array}{c}(6.5 \sim 6.6) \\
-1 \%\end{array}$ & $\begin{array}{c}(3.6 \sim 3.8) \\
0 \%\end{array}$ & $\begin{array}{r}(0.27) \\
+8 \%\end{array}$ & Many & TTL & Many \\
\hline $\begin{array}{l}\text { Central } \\
\text { Basin }\end{array}$ & $\begin{array}{l}(20 \sim 50) \\
-16 \%\end{array}$ & $\begin{array}{c}(6.6 \sim 6.7) \\
0 \%\end{array}$ & $\begin{array}{c}(3.6 \sim 3.8) \\
0 \%\end{array}$ & $\begin{array}{l}(0.27) \\
+8 \%\end{array}$ & Many & None & Slight \\
\hline $\begin{array}{l}\text { Oou } \\
\text { Mountain } \\
\text { Range }\end{array}$ & $\begin{array}{c}(500 \sim 1000) \\
+103 \%\end{array}$ & $\begin{array}{c}(6.6 \sim 6.7) \\
-1 \%\end{array}$ & $\begin{array}{c}(3.6 \sim 3.8) \\
0 \%\end{array}$ & $\begin{array}{l}(0.26) \\
+4 \%\end{array}$ & Two & $\begin{array}{l}\text { VF } \\
\text { HTL }\end{array}$ & Slight \\
\hline $\begin{array}{l}\text { Miyagi-ken- } \\
\text { Hokubu }\end{array}$ & $\begin{array}{l}(2000) \\
\text { local } \\
\text { minimun }\end{array}$ & $\begin{array}{l}(7.0) \\
\text { c.f. Upper } \\
\text { Crust }\end{array}$ & $\begin{array}{c}(3.9 \sim 4.0) \\
5 \%\end{array}$ & $\begin{array}{c}(0.28) \\
+12 \%\end{array}$ & None & MSL & Many \\
\hline
\end{tabular}

et al., 1997 and references therein for further details).

They are summarized as:

1) In the major fracture zones at the western and eastern sides of the Central Basin, there is a good correlation between resistivity contrasts, faults or geological alignments and seismicity.

2) The Central Mountain Range and the Dewa Hill are both characterized by resistive bodies, but with different seismicity.

3) Active seismicity around the boundaries of the Central Basin and the Central Mountain Range may be due to a buried fault.

4) Many of the faults associated with scarce seismicity are characterized by higher resistivities. 
The seismic velocity data (Zhao et al., 1992) have been used to provide insight into the complex relation between particular seismic activity and crustal regime. The P-wave velocity $(V p)$ and $\mathrm{S}$-wave velocity $(V s)$ are shown in Figs. 3(c) and 3(d) for the upper crust $(H=7.5 \mathrm{~km})$, respectively, and in Figs. 4(c) and 4(d) for the lower crust $(H=22.5 \mathrm{~km})$. The Poisson ratio $\sigma$ deduced from the $V p$ and $V s$ values is also included in Figs. 3(e) and 4(e), respectively.

Several interesting correlations between the seismicity and these new geophysical data sets emerge in various zones. In Tables 1 and 2, we have semi-quantitatively summarized the features of geological and geophysical data at these zones in the upper crust, and in the lower crust, respectively, for the sake of convenience.

The Asahi Mountain Range, with many of active faults, is contrasted from the central Mountain Range in the sense that the former is seismically much less active than the latter (Fig. 3(a)). In terms of resistivity distribution, both are marked by nearly equal high resistivity (Table 1). The other striking difference is that relatively low values of the Poisson ratio $(\sim 0.20-0.22)$ prevail beneath the Central Mountain Range compared with the Asahi Mountain Range. This can be construed as being a pointer towards the relatively poor saturation (fluid) state of rocks beneath the Central Mountain range. The fluid poor state in the Central Mountain Range may be related with the volcanism (Yokokura et al., 1998). The inference is in accordance with the absence of enhanced conductivity in the lower crust (Fujinawa et al., 1999). It may be argued that seismicity, particularly microearthquakes, in the brittle crust of this region, may be activated by tectonic stress rather than the physical state of the medium. The situation may be similar to the upper crust in the rupture zone of the Kobe earthquake inferred using seismic velocity and Poisson ratio data (Zhao and Negishi, 1998). They found that high aftershock activity generally occurred in the region of low Poisson ratios, and inferred that the region is a strong part of the fault zone.

The fracture zone in the west of the Central Basin shows an exceedingly small Poisson ratio value of 0.20 that varies in the interval $0.20 \sim 0.30$. Here the seismic velocity $V s$ is large, which is in line with the case beneath the Central Mountain Range. Another common feature in the two regions is that there are no big earthquakes, suggesting that strains cannot be accumulated long enough to trigger a large-scale rupture.

In the Miyagi-ken-hokubu region, large earthquakes have occurred twice during the 20th century. The zone is characterized as conductive and has a local maximum of Poisson ratio, suggesting a relatively fluid-rich state. Moreover, the $V p$ is found to be largest in the area thus indicating the rather brittle nature of the crust. The correlation in velocities is the same as that at the Coso Hot Springs (Wu and Lees, 1999) which points at the fluid saturation. A situation resembles the main shock zone of the Kobe earthquake (Zhao and Negishi, 1998). However, the correspondence with the Kobe earthquake is not within the whole parameters of seismic velocity: the $V p$ is low in the case of the Kobe earthquake. Therefore, the $V p$ and $V s$ are thought not to be dominant parameters explaining seismic activity (Aprea et al., 1998;
Zhao and Negishi, 1998).

The low values of the Poisson ratio in the Central Basin and Central Mountain Range does not extend to the lower crust (Table 2) clearly suggesting the different character of the lower compared with the upper crust, in conformity with the difference in seismicity. On the other hand, we note that the conductivity and the $V p$ are both anomalous in the whole crust in the Miyagi-ken-hokubu earthquake zone. It is suggested that the entire crust is anomalous, indicating large-scale heterogeneity in the region.

\section{Concluding Remarks}

Wideband MT observations were made at 91 sites along three long transects, supplemented by three short transects in the north, taken from the data of previous surveys in the northeastern Japan Arc. Following previous work (Fujinawa et al., 1999) on the interpretation of seismicity in the central part of the northeastern Japan Arc and on the basis of conductivity, we investigated a variety of seismic activities using additional MT data and the seismic velocity data of Zhao et al. (1992).

The present analyses show that the use of the seismic velocity and Poisson ratio, in addition to conductivity data, can be helpful in the interpretation of seismicity by parameterizing the state of the rock, including the degree of fluid content. However, the various patterns of parameter values correspond to seismicity with the result that no definitive inference can be drawn from presently available data. Higher spatial resolution in the conductivity, seismic velocity, Poisson ratio would be very useful in producing a clear picture of the seismotectonics in the given area.

Acknowledgments. The authors express their sincere thanks to Dr. Shigetsugu Uyehara and Profs. Yukio Hagiwara, Sachio Nabetani, and Yoshinori Honkura for their constant encouragement. Thanks are also expressed to Profs. Nobuaki Niizuma and Yoshihiro Suzuki for valuable discussions and suggestions, and to the many organizations and institutes that helped with the experiments. We greatly thank Prof. Zhao Da Peng for providing the programs to calculate seismic velocity. Our thanks also go to Ms. Yumiko Yamauchi and Mr. Wu Yuesheng for preparing the manuscript. The Science and Technology Agency Japan (now the Ministry of Education, Sports, Culture, Science and Technology) funded the study for the Promotion of Surveys and Research on Earth Science and Technology and Ocean Development.

\section{References}

Active Fault Research Group, Active Faults in Japan, 437 pp., University of Tokyo Press, Tokyo, 1991.

Aprea, C., M. Unsworth, and J. Booker, Resistivity structure of the Olympic Mountains and Puget Lowlands, Geophys. Res. Lett., 25, 109-112, 1998.

Chen, L., J. R. Booker, A. G. Jones, N. Wu, M. J. Unsworth, W. Wei, and H. Tan, Electrically conductive crust in Southern Tibet from INDEPTH magnetotelluric surveying, Science, 274, 1694-1696, 1996.

Fujinawa, Y., N. Kawakami, T. H. Asch, M. Uyeshima, and Y. Honkura, Studies of the Georesistivity structure in the central part of the northeastern Japan Arc, J. Geomag. Geoelectr., 49, 1601-1617, 1997.

Fujinawa, Y., N. Kawakami, J. Inoue, T. H. Asch, S. Takasugi, and Y. Honkura, 2-D georesistivity structure in the central part of the northeastern Japan arc, Earth Planets Space, 51, 1035-1046, 1999.

Gamble, T. D., W. M. Goubau, and J. Clarke, Magnetotellurics with a remote reference, Geophysics, 44, 53-68, 1979.

Geological Survey of Japan, Geological Map of Japan 1:1,000,000, Geological Survey of Japan, 1995.

Groom, R. W. and R. C. Bailey, Decomposition of magnetotelluric impedance tensors in the presence of local three-dimensional galvanic 
distortions, J. Geophys. Res., 94, 1913-1925, 1989.

Hasegawa, A., D. Zhao, S. Hori, A. Yamamoto, and S. Horiuchi, Deep structure of the northeastern Japan arc and its relationship to seismic and volcanic activity, Nature, 352, 682-689, 1991.

Honkura, Y., Electrical conductivity structure in the upper mantle and its implications for the origin of magma, Kazan, 2(33), 203-212, 1988.

Horiuchi, S., H. Ishii, and A. Takagi, Two-dimensional depth structure of the crust beneath the Tohoku District, the northeastern Japan arc, I, Method and Conrad discontinuity, J. Phys. Earth, 30, 47-69, 1982.

Jones, A. G., Electrical conductivity of the continental lower crust, in Continental Lower Crust, edited by D. M. Fountain, R. J. Arculus, and R. W. Kay, Elsevier, New York, 1992.

Kawakami, N., Y. Fujinawa, T. H. Asch, and S. Takasugi, Local three dimensional galvanic distortions in the central part of northeastern Japan, J. Geomag. Geoelectr., 49, 1387-1400, 1997.

Lee, K. H., K. Yamane, and S. Takasugi, A new 2-D inversion scheme for magnetotelluric data using a modified RRI method, Proceedings of the World Geothermal Congress 2, pp. 915-920, 1995.

Nabetani, S. and M. Fukuta, Conductivity structure of crust and mantle in the Northeastern Japan prospected by MT and GEMIT method, 10. Backbone Mountainland, Aomori, Sci. Rep. Hirosaki Univ., 42, 53-60, 1995.

Nabetani, S., K. Maekawa, and K. Uchida, Conductivity structure of crust and mantle in the Northeastern Japan prospected by MT and GEMIT method, 1. East to west section along $40^{\circ} 40^{\prime} \mathrm{N}$ traverse, Sci. Rep. Hirosaki Univ., 39, 37-46, 1992.

Ogawa, Y., Deep crustal resistivity structure revealed by sideband magnetotellurics-Tohoku and Hokkaido region, University of Tokyo, 1992.

Sato, H., I. S. Sacks, and T. Murase, The use of laboratory velocity data for estimating temperature and partial melt fraction in the low velocity zone: comparison with heat flow and electrical conductivity studies, $J$. Geophys. Res., 94, 5689-5704, 1989.

Schultz, A. P. and R. S. Crosson, Seismic velocity structure across the
Central Washington Cascade Range from refraction interpretation with earthquakes sources, J. Geophys. Res., 101, 27899-27915, 1996.

Simpson, F., Stress and seismicity in the lower-continental crust: a challenge to simple ductility and implication for electrical conductivity mechanisms, The 14th Workshop on Electromagnetic Induction in the Earth, pp. 215-228, 1998.

Smith, J. T. and J. R. Booker, Rapid inversion of two and three dimensional magnetotelluric data, J. Geophys. Res., 96, 3905-3922, 1991.

Umino, N. and A. Hasegawa, Inhomogeneous structure of the crust and its relationship to earthquake ocurrence, in Seismotectonics in Convergent Plate Boundary, pp. 225-235, 2002.

Utada, H., A direct inversion method for two-dimensional modeling in the geomagnetic induction problem, Doctoral thesis, University of Tokyo, 1987.

Wu, H. and J. M. Lees, Three-dimensional P and S wave velocity structures of the Coso Geothermal Area, California, from microseismic travel time data, J. Geophys. Res., 104, 13217-13233, 1999.

Yamane, K., S. Takasugi, and K. H. Lee, A new magnetotelluric inversion scheme using generalized RRI method and case studies, Geophysics, 35, 209-213, 1996.

Yokokura, T., T. Miyazaki, N. Kano, and K. Yamaguchi, Lower crustal and sub-crustal reflectors beneath the southern Kit akami area, Abst. 1998 Japan Earth and Planetary Science Joint Meeting, pp. 363, 1998.

Zhao, D. and H. Negishi, The 1995 Kobe earthquake: Seismic image of the source zone and its implications for the rupture nucleation, J. Geophys. Res., 103(B5), 9967-9986, 1998.

Zhao, D., A. Hasegawa, and S. Horiuchi, Tomographic imaging of P and W wave velocity structure beneath Northeastern Japan, J. Geophys. Res., 97, 19909-19928, 1992.

Y. Fujinawa (e-mail: fujinawa@bosai.go.jp), N. Kawakami, J. Inoue, T. H. Asch, and S. Takasugi 